\title{
(2) OPEN ACCESS \\ Feasibility of intra-amniotic digoxin administration by obstetrics and gynecology trainees to induce fetal demise prior to medical abortion beyond 20 weeks
}

\author{
Tesfaye Hurissa Tufa (D) , ${ }^{1,2}$ Antonella Francheska Lavelanet, ${ }^{2}$ \\ Lemi Belay, ${ }^{1,2}$ Berhanu Seboka, ${ }^{1}$ Jason Bell ${ }^{3}$
}

${ }^{1}$ Obstetrics and Gynecology, Saint Paul's Hospital Millennium Medical College, Addis Ababa, Ethiopia

${ }^{2}$ Sexual and Reproductive Health and Research, World Health Organization, Geneva, Switzerland

${ }^{3}$ Obstetrics and Gynecology, University of Michigan, Ann Arbor, Michigan, USA

Correspondence to Dr Tesfaye Hurissa Tufa, Obstetrics and Gynecology, Saint Paul's Hospital Millennium Medical College, Addis Ababa, Oromia, Ethiopia; tesfaye. hurisa@sphmmc.edu.et

Received 20 May 2019 Revised 27 February 2020 Accepted 11 March 2020 Published Online First 2 April 2020
A Check for updates

(C) World Health Organization 2020. Licensee BMJ.

To cite: Tufa TH, Lavelanet AF, Belay L, et al. BMJ Sex Reprod Health 2020;46:308-312.

\begin{abstract}
Background Transient fetal survival is one issue that providers may face while managing late second-trimester abortion. Induction of fetal demise using digoxin and other means has been widely performed by maternal-fetal medicine and family planning subspecialists worldwide. However, there are no data available in Ethiopia as regards preventing transient fetal survival in late second-trimester medical termination of pregnancy.

Objective The objective of the study was to document the feasibility of intra-amniotic digoxin administration for inducing fetal demise prior to medical abortion beyond 20 weeks of gestational age. Additionally, we aimed to demonstrate that this skill could be transferred to obstetrics and gynaecology residents at St Paul's Hospital Millennium Medical College in Addis Ababa, Ethiopia.

Methods A retrospective cross-sectional study design was conducted to document the feasibility, safety and effectiveness of intraamniotic digoxin. A structured questionnaire was used to collect selected sociodemographic data and clinical characteristics. Data were entered and analysed using SPSS statistical package version 20.
\end{abstract}

Results During the study period, 49 women received intra-amniotic digoxin. The success rate of intra-amniotic digoxin in this study was $95.9 \%$. Thirty-seven (75.5\%) procedures were performed by obstetrics and gynaecology residents and 12 (24.5\%) were performed by family planning faculties. There were two out of hospital expulsions with no signs of life, and no other serious maternal complications were observed.

\section{Key messages}

$\Rightarrow$ Commencement of intra-amniotic digoxin to induce fetal demise in an established academic centre facilitates feasibility and sustainability of the service.

$\Rightarrow$ The skill of intra-amniotic digoxin administration can be transferred to trainees and be incorporated into standard of care.

Conclusion It is feasible for obstetrics and gynaecology trainees in Ethiopia to learn how to safely administer intra-amniotic digoxin to induce fetal demise for induced medical terminations.

\section{INTRODUCTION}

Worldwide there are 35-40 abortions per 1000 women of reproductive age. ${ }^{1}$ Abortion rates are about 25\% higher in low-income countries as compared with high-income countries. ${ }^{2}$ Most induced abortions globally are performed in the first trimester ( $\leq 13$ weeks); however, in Ethiopia, a significant number of induced abortions are performed in the second trimester. ${ }^{3}$ A recent study in the northern region of Ethiopia conducted between 2013 and 2014 demonstrated that as many as $19.2 \%$ of induced abortions are performed in the second trimester. ${ }^{4}$ Delay in seeking abortion care can be related to a variety of psychosocial reasons. A study in Ethiopia showed that irregular menstrual cycles, delayed recognition of pregnancy symptoms, and other logistical problems, including obtaining financing for 
the abortion and lack of information about where to find the service, were some of the reasons for women presenting in the second trimester. ${ }^{4}$ Similarly, a study in South Africa showed that these reasons are complex and are linked to changes in personal circumstances, often leading to indecision, delays in detecting a pregnancy, and health service-related barriers that hindered access to abortion services. ${ }^{5}$

With advancing gestational age, the incidence of transient fetal survival with medical abortion is increased. The World Health Organization (WHO) recommends that fetal demise should be considered when terminating pregnancy beyond 20 weeks. $^{6}$ Additionally, the Royal College of Obstetricians \& Gynaecologists recommends inducing fetal demise prior to performance of all medical abortions at gestations greater than 21 weeks and 6 days. ${ }^{7}$ One of the pharmacological agents used to induce fetal demise is digoxin. ${ }^{8}$ Clinicians have been using digoxin to facilitate second-trimester pregnancy termination for several years. ${ }^{9}$ Administration can be via intra-cardiac, intra-thoracic, intra-fetal and intra-amniotic routes, with doses varying from 0.25 to $2 \mathrm{mg} .{ }^{10}$ Evidence from studies has demonstrated a success rate of $93 \%$ to $100 \% .{ }^{11-13}$ The procedure is generally safe; however, complications can include infection, hospital admission, and unplanned delivery of the fetus. ${ }^{9} 1415$

Multiple studies have demonstrated the safety and effectiveness of digoxin in inducing fetal demise when performed by family planning and maternal-fetal medicine subspecialists. ${ }^{11-15}$ A study by Dean et al has also demonstrated the feasibility of safe performance of the procedure by residents under direct supervision by specialists. ${ }^{12}$

Ethiopia has expanded its abortion law since 2005 and has included a spectrum of indications to improve access to abortion services. ${ }^{16} \mathrm{~A}$ pregnancy resulting from rape or incest, a fetus with a serious, incurable deformity, and physical/mental deficiency of the pregnant women are some of the legal indications incorporated in the new abortion law. ${ }^{17}$ The law allows termination of pregnancy until 27 completed weeks. ${ }^{17}$ With more than $8 \%$ of abortions in the country taking place during the second trimester, ${ }^{18}$ evidence of signs of life with transient fetal survival following late secondtrimester medical abortion is a common phenomenon. Currently in Ethiopia there is no practice of inducing fetal demise before second-trimester termination of pregnancy by any provider, including maternal fetal medicine specialists. At Saint Paul's Hospital Millennium Medical College, the family planning faculty initiated a policy of intra-amniotic digoxin administration for all patients undergoing medical abortion beyond 20 weeks. Digoxin is used because its use is simple to teach, facilitating transfer of skills to residents participating in abortion services. The administration of digoxin is now incorporated into the routine care of induced termination of pregnancy beyond 20 weeks managed by fellows.

The purpose of the study was to document the feasibility of intra-amniotic administration of digoxin by resident trainees during the period 1 January 2018 to 30 June 2018.

\section{METHODS}

\section{Study area and study period}

The study was conducted in St Paul's Hospital Millennium Medical College, a tertiary referral and teaching hospital, in Addis Ababa, Ethiopia between January 2018 and June 2018. At this hospital, obstetrics and gynaecology residents rotate to the family planning clinic throughout the 4 years of training. Intra-amniotic digoxin administration is one of the skills taught on the family planning service.

\section{Technique for transabdominal digoxin injection}

Following a new standard of care introduced in the institution related to medical abortion beyond 20 weeks, all women who met the criteria for induction of fetal demise and had no contraindication for digoxin were provided with ultrasound-guided transabdominal intra-amniotic digoxin. All cases were dated by ultrasound using fetal biometry; head circumference, abdominal circumference and femur length. Once dating was established, intra-amniotic injection of $1 \mathrm{mg}$ digoxin was undertaken. Following digoxin administration, all women were observed clinically for $30 \mathrm{~min}$ for any drug-related complications. During this time, pulse rate and blood pressure were recorded. Residents on the family planning service first observed the faculty perform the procedure. Once the residents felt comfortable with the steps, they then started conducting the injections under observation by the faculty. As per the abortion protocol of the hospital, $200 \mathrm{mg}$ mifepristone was also given orally on the same day with digoxin. After this, patients were given an appointment to return 48 hours later when the fetal cardiac activity was checked, and they were admitted for misoprostol $(200-400 \mu \mathrm{g})$ administration.

\section{Patient and public involvement statement}

Patients and public were not involved in this study.

\section{Study design and sample}

This was a retrospective cross-sectional study where all the clinical records of women who received intra-amniotic digoxin during the study period were reviewed.

\section{Variables and measurements}

A structured data collection questionnaire was prepared in English and used to collect clinical variables and sociodemographic data from the patients' charts. We reviewed women's medical and obstetric profiles, as well as relevant documentation related to 
Table 1 Gestational age of the study participants

\begin{tabular}{lc}
\hline Gestational age (weeks) & Women (n (\%)) \\
\hline $20-21.6$ & $7(14.2)$ \\
\hline $22-23.6$ & $21(42.9)$ \\
$\geq 24$ & $21(42.9)$
\end{tabular}

digoxin administration, including dose, documentation of fetal heartbeat before admission for misoprostol, and the presence of any complications following intra-amniotic digoxin administration.

\section{Data processing and analysis}

The data was entered into SPSS (version 20) software. Descriptive data analysis was performed using frequency and percentage.

\section{Ethical considerations}

The study was conducted after receiving an official letter of clearance from the St Paul's Hospital Millennium Medical College ethical review committee.

\section{RESULTS}

In the study period from January 2018 to June 2018, 49 women who presented for elective termination of pregnancy beyond 20 weeks received transabdominal intra-amniotic digoxin to induce fetal demise.

The median age of the study participants was 23.4 (range 18-34) years. All 49 women presented for medical-induced abortion between 20 and 27 completed weeks. The median gestational age was 23.1 weeks, although nearly $43 \%$ of the women's gestational age was $\geq 24$ weeks (table 1 ).

All 49 women had documentation of an obstetric ultrasound. In $75.5 \%$ of cases intra-amniotic digoxin was administered by residents, and in $25.5 \%$ of cases it was performed by family planning faculty. Twelve $(24.5 \%)$ women presented earlier than instructed ( $<48$ hours post-digoxin administration). In 35 (71.4\%) women, fetal cardiac activity was checked 48 hours after administration of digoxin. Except in two patients who received $0.5 \mathrm{mg}$ and $0.75 \mathrm{mg}$ digoxin, all the other patients $(n=47)$ received the standard $1 \mathrm{mg}$ digoxin dose; the reason for the differing dose administration was not specified on the clinical charts.

In $44(89.8 \%)$ women there was no detected fetal cardiac activity following intra-amniotic digoxin administration. In five cases, fetal cardiac activity was positive following digoxin administration. For these cases, a repeat dose of digoxin was administered, and negative fetal cardiac activity was achieved 24 hours later in three cases yielding an overall success rate of 95.9\%. In two cases, a repeat dose was unsuccessful; these cases were admitted for misoprostol administration with positive fetal cardiac activity. Fetal viability on expulsion was not documented on the clinical chart.
Table 2 Clinical characteristics of women with positive fetal cardiac activity following digoxin administration

\begin{tabular}{lllll}
\hline Case & $\begin{array}{l}\text { Gestational } \\
\text { age (weeks) }\end{array}$ & $\begin{array}{l}\text { Digoxin } \\
\text { dose } \\
\text { (mg) }\end{array}$ & $\begin{array}{l}\text { Time between } \\
\text { digoxin and US } \\
\text { detection of } \\
\text { cardiac activity } \\
\text { (hours) }\end{array}$ & $\begin{array}{l}\text { Cardiac } \\
\text { activity } \\
\text { after repeat } \\
\text { dose of } \\
\text { digoxin }\end{array}$ \\
\hline 1 & 24 & 1 & 24 & Negative \\
\hline 2 & 24.6 & 1 & 24 & Negative \\
\hline 3 & 21.4 & 1 & 48 & Negative \\
\hline 4 & 27 & 1 & 48 & Positive \\
\hline 5 & 25 & 1 & 48 & Positive \\
\hline US, ultrasound. & & & \\
\hline
\end{tabular}

All the five women with positive fetal cardiac activity received the standard $1 \mathrm{mg}$ digoxin dose, and four of them were $\geq 24$ weeks' gestation (table 2).

The study participants experienced few complications. Two (4\%) women expelled the conceptus outside the hospital, and two others (4\%) experienced vomiting on the day of digoxin administration. The two women who expelled the conceptus outside the hospital were later evaluated in the hospital (after expulsion). They were found to have complete expulsion (fetus and placenta), reported no signs of fetal life on delivery, and were discharged on the same day of evaluation. At the time of presentation to the hospital for admission, no women experienced fever, rigour chills, offensive vaginal discharge or gush of fluid per vagina prior to expulsion. No participant also experienced clinically detectable cardiovascular sequelae following the injection of the drug.

\section{DISCUSSION}

Following the country's commitment to reducing maternal death related to unsafe abortion, all stakeholders in Ethiopia are striving to increase access and quality of care provided for individuals seeking reproductive health services. As a tertiary care hospital, Saint Paul's Hospital Millennium Medical College receives the majority of late second-trimester abortion referrals from neighbouring health centres and hospitals.

The issue of transient fetal survival is inevitable in the provision of medical abortion in the second trimester, especially in countries like Ethiopia where the gestational age for fetal viability extends to 27 completed weeks. ${ }^{17}$ In Ethiopia, even though there has been no study on the magnitude of the problem related to transient fetal survival or its related effects, clinical reports suggest that the management of transient survival can be quite complicated for the abortion provider (personal communications with healthcare providers). Providers may also be worried about the potential legal implications of an unintended live birth. ${ }^{6}$

Additionally, transient fetal survival may complicate the abortion process for the woman herself, or for 
other members of the care group who may attempt futile resuscitation of a non-viable fetus. ${ }^{9}$ With guaranteed demise prior to the procedure, healthcare providers and women can avoid situations where there may be transient fetal life. ${ }^{15}$

Existing evidence demonstrates that induction of fetal demise using various routes can be safely practised following adequate training and in the presence of an adept provider. ${ }^{11}{ }^{19}$ While data regarding the safety of inducing fetal demise by trainees is relatively limited, in this study we have demonstrated that with proper training, residents can safely and effectively administer intra-amniotic digoxin after being taught the procedure by family planning faculty.

The study demonstrated an overall success rate of 95.9\%. This rate is in line with the success rates of other studies, which are between $93 \%$ and $100 \% .{ }^{11-13}$ Existing studies on the practice of feticide generally focus on pregnancies with gestational ages below 24 weeks. ${ }^{9}{ }^{11} 1214$ In our study, $43 \%$ of the women were $\geq 24$ weeks' gestation. Interestingly, there were two women in this study with continuing fetal cardiac activity after a second digoxin injection. Both of these women had gestational ages $>25$ weeks.

The study was conducted in an established tertiary centre, where specialised services are already provided, thereby potentially making the intervention more feasible. Furthermore, sustainability of such services is likely as the study was conducted in an academic centre, where there are opportunities for continuous knowledge and skill transfer between the family planning faculty and residents. There are, however, several limitations of this study. Primarily, the number of women in this study is small, thereby providing only initial information relating to the safe and effective administration of digoxin by trainees. Other methods of preventing transient fetal survival, such as transection of the umbilical cord or investigation of other medications used in feticide, have not been undertaken in this setting. Additionally, there is no established number of cases or procedures to be performed by the trainees to ensure proficiency. So, continuing competencies will be needed to ensure sustained delivery of quality care.

Despite its limitations, this study is the first to explore the feasibility of digoxin administration for the purposes of inducing fetal demise by resident trainees in Ethiopia. Acquiring this skill means that providers are better equipped to manage late secondtrimester abortion beyond 20 weeks and can address potential concerns that women and other members of the care group may have relating to transient fetal survival. Moreover, following the integration into clinical care, the residents have now made administration of intra-amniotic digoxin a part of routine care for women seeking medical abortion beyond 20 weeks.

\section{CONCLUSIONS}

While our study was limited to only 49 women, the results demonstrate the feasibility of intra-amniotic digoxin administration for the prevention of transient fetal survival. Furthermore, this procedure can be completed by trainees following proper training and skill transfer. With the integration of the family planning programme and the growing number of abortion cases in Ethiopia, this skill transfer and sustained knowledge translates into improved patient care.

Contributors THT: principal investigator from proposal writing up to final write up. AFL: participated in manuscript preparation and editing. JB: participated in data collection, manuscript preparation and editing. LB: participated in data collection. BS: participated in data collection.

Funding The authors have not declared a specific grant for this research from any funding agency in the public, commercial or not-for-profit sectors.

Competing interests None declared.

Patient and public involvement Patients and/or the public were not involved in the design, or conduct, or reporting, or dissemination plans of this research.

Patient consent for publication Obtained.

Ethics approval The study received clearance from the St Paul's Hospital Millennium Medical College ethical review committee.

Provenance and peer review Not commissioned; externally peer reviewed.

Data availability statement Data are available in a public, open access repository. All data relevant to the study are included in the manuscript or uploaded as supplementary information.

Open access This is an open access article distributed under the terms of the Creative Commons Attribution IGO License (CC BY 3.0 IGO), which permits use, distribution, and reproduction in any medium, provided the original work is properly cited. In any reproduction of this article there should not be any suggestion that WHO or this article endorse any specific organization or products. The use of the WHO logo is not permitted. This notice should be preserved along with the article's original URL.

Disclaimer: The author is a staff member of the World Health Organization. The author alone is responsible for the views expressed in this publication and they do not necessarily represent the views, decisions or policies of the World Health Organization.

\section{ORCID iD}

Tesfaye Hurissa Tufa http://orcid.org/0000-0002-8623-9113

\section{REFERENCES}

1 Sedgh G, Bearak J, Singh S, et al. Abortion incidence between 1990 and 2014: global, regional, and subregional levels and trends. Lancet 2016;388:258-67.

2 LaVecchia C. Recent trends in induced abortions: a global perspective. Epidemiol Biostat Public Health 2018;15:e12924.

3 Boland R. Second trimester abortion laws globally: actuality, trends and recommendations. Reprod Health Matters 2010;18:67-89.

4 Mulat A, Bayu H, Mellie H, et al. Induced second trimester abortion and associated factors in Amhara region referral hospitals. Biomed Res Int 2015;2015:1-6. 
5 Harries J, Orner P, Gabriel M, et al. Delays in seeking an abortion until the second trimester: a qualitative study in South Africa. Reprod Health 2007;4:7.

6 World Health Organization (WHO). Safe abortion: technical \& policy guidance for health systems. 2nd edn. Geneva: WHO Press, 2015.

7 Royal College of Obstetricians and Gynaecologists (RCOG). Report of the RCOG Ethics Committee on a consideration of the law and ethics in relation to late termination of pregnancy for fetal abnormality. London: RCOG, 1998.

8 Diedrich J, Drey E, Society of Family Planning. Induction of fetal demise before abortion. Contraception 2010;81:46273.

9 Drey EA, Thomas LJ, Benowitz NL, et al. Safety of intraamniotic digoxin administration before late second-trimester abortion by dilation and evacuation. Am J Obstet Gynecol 2000;182:1063-6.

10 Hern WM, Zen C, Ferguson KA, et al. Outpatient abortion for fetal anomaly and fetal death from 15-34 menstrual weeks' gestation: techniques and clinical management. Obstet Gynecol 1993;81:301-6.

11 Jackson RA, Teplin VL, Drey EA, et al. Digoxin to facilitate late second-trimester abortion: a randomized, masked, placebo-controlled trial. Obstet Gynecol 2001;97:471-6.
12 Molaei M, Jones HE, Weiselberg T, et al. Effectiveness and safety of digoxin to induce fetal demise prior to secondtrimester abortion. Contraception 2008;77:223-5.

13 Sharvit M, Klein Z, Silber M, et al. Intra-amniotic digoxin for feticide between 21 and 30 weeks of gestation: a prospective study. BJOG 2019;126:885-9.

14 Steward R, Melamed A, Kim R, et al. Infection and extramural delivery with use of digoxin as a feticidal agent. Contraception 2012;85:150-4.

15 Paul M, Lichtenberg S, Borgatta L. Management of unintended and abnormal pregnancy: comprehensive abortion care. Hoboken, NJ: Wiley-Blackwell, 2009.

16 Federal Democratic Republic of Ethiopia Ministry of Health. Health sector development program IV, 2010/11-2014/15. Addis Ababa, Ethiopia, 2010.

17 Federal Ministry of Health. Technical and procedural guidelines for safe abortion services in Ethiopia. 2nd edn, 2013.

18 Gebrehiwot Y, Fetters T, Gebreselassie H, et al. Changes in morbidity and abortion care in Ethiopia after legal reform: national results from 2008 and 2014. Int Perspect Sex Reprod Health 2016;42:121-30.

19 Tocce K, Sheeder JL, Edwards LJ, et al. Feasibility, effectiveness and safety of transvaginal digoxin administration prior to dilation and evacuation. Contraception 2013;88:706-11. 